\title{
A CIDADE DE CÁCERES: HISTÓRIA E MEMÓRIA DO PROCESSO ELEITORAL
}

\author{
JUCINEIA SERAGLIO; NEUZA B. DA SILVA ZATTAR
}

Programa de Pós-Graduação em Linguística, Universidade do Estado de Mato Grosso Av. Santos Dumont s/n - Bloco II. Centro de Pesquisa e Pós-Graduação em Linguagem, Cidade Universitária, Bairro DNER, 78 200-000 - Cáceres - MT, Brasil

jucineiaseraglio@gmail.com ; neuza.zattar@gmail.com

\begin{abstract}
Resumo. Este artigo ${ }^{1}$ reflete sobre as propagandas eleitorais dos candidatos a cargo de prefeito da cidade de Cáceres-MT para o mandato de 2013-2016, e sobre os modos de instalação desses materiais nos espaços públicos urbanos, a partir de concepções sobre a cidade pelo viés da história, da sociologia, da análise do discurso e da arquitetura, buscando compreender como a cidade é pensada na sua espessura material e histórica, para cada uma dessas áreas do conhecimento. Para essa reflexão, discutimos a constituição histórico-social do processo eleitoral na cidade de Cáceres, bem como o surgimento das propagandas eleitorais, por envolver a relação entre língua, sujeito e história.
\end{abstract}

Palavras-chave: enunciado; cidade; campanha eleitoral.

\begin{abstract}
This article reflects on the electoral advertisements of candidates for the post of mayor of Cáceres-MT for the term of 2013-2016, and it analyses the way these materials are installed in urban public spaces, from conceptions over the city and the perspective of history, sociology, discourse analysis and architecture, trying to understand how the city is planned in its material and historical values, for each of these areas of knowledge. It is also discussed the historical and social constitution of the electoral process in the city of Cáceres, as well as the rise of electoral advertisements, because it involves the relationship between language, subject and history.
\end{abstract}

Keywords: enunciation; city; election campaign.

\section{Introdução}

Muitas são as formas de significar a cidade, não só pelas formas físicas, naturais, imagens, cores, ruídos como também pela linguagem que nela se espacializam e pelos sujeitos que nela transitam e se movimentam, estabelecendo interlocuções diárias com a cidade e com outros sujeitos. Enquanto símbolo de sociabilidade humana, lugar de encontro, desencontro e de vida em comum, a cidade é também um símbolo da

\footnotetext{
${ }^{1}$ É um recorte da minha dissertação de mestrado realizada em 2015, sob a orientação da Profa. Dra. Neuza B. da Silva Zattar, em que analisamos como a cidade de Cáceres-MT, localizada a $205 \mathrm{~km}$ de Cuiabá, capital do Estado de Mato Grosso, significa e é significada nas propagandas político-partidárias de candidatos à Prefeitura Municipal, expostas em diferentes materialidades nos espaços públicos centrais e não centrais, no período eleitoral do ano de 2012.
} 
diversidade humana, pois é nesse "habitat urbano" que o sujeito citadino significa e é significado.

$\mathrm{Na}$ contemporaneidade, a cidade toma a forma de um mosaico de formas e linguagens que joga com outras palavras/outros espaços, lugar de distintas linguagens e sujeitos. Le Goff (1998, p. 143) diz que "a cidade contemporânea escapa às definições tradicionais [...], o passado se esquiva àquilo que lhe pede o presente".

Até os últimos tempos, conforme Lefebvre (2001), a cidade era vista pelo pensamento teórico como uma entidade que refletia simplesmente nela a história geral. $\mathrm{Na}$ atualidade começa-se a apreender a especificidade da cidade, nas relações com a sociedade no seu conjunto, seu funcionamento, sua composição e também com a sua história. Nas palavras do autor a cidade é a obra de uma história, ou seja, de pessoas e de grupos em condições sócio-históricas, que realizam essa obra com determinação. Para Lefebvre (idem, p. 52), "a cidade é obra a ser associada mais com a obra de arte do que com o simples produto material", pois se há uma produção da cidade e das relações sociais na cidade, a produção e reprodução são de "seres humanos por seres humanos", sendo mais do que uma produção de objetos.

Weber (1979 apud ORLANDI, 2004, p. 12) diz que "a cidade surge como um dos resultados e ao mesmo tempo como um pressuposto do desenvolvimento capitalista". Na visão do sociólogo, a cidade é significada como um aglomerado de instituições política, administrativa e jurídica, incluindo a questão da cidadania e urbanidade.

Orlandi (2001) considera a cidade como um espaço que significa e que é significado, ao significar a cidade o sujeito se significa na e pela cidade. Nessa direção, a autora (idem, p. 8) pensa a cidade como "o olho que busca a individualidade tirando partido (e sucumbindo) da dispersão. [...] "prismas" diferentes convivendo em quantidade concentrada em um mesmo espaço simbólico". Essas relações de sentidos, segundo Orlandi, não são de conteúdo, nem são divisões, são movimentos de distintas formas na relação espaço-tempo.

Nos estudos urbanos que desenvolve, Rolnik $(1988$, p. 8) considera a cidade como "uma obra coletiva que desafia a natureza", pois, ao nascer com a sedentarização a cidade delimita uma nova relação homem/natureza: a necessidade de gestão da produção coletiva. Do ponto de vista da autora, a cidade pode ser pensada como ímã ou como escrita, pois "construir e morar em cidades implica necessariamente viver de forma coletiva" (idem, p. 19).

A cidade pensada na sua espessura material e histórica significa concebê-la como espaço simbólico de produção e confronto de sentidos. Para Mota (2013), o termo espaço é visto como um lugar atravessado pela memória e na qual o sujeito se inscreve historicamente, produzindo sentidos. Como afirma Pfeiffer (2001, p. 32),

No caso da cidade, tomamos lugar como local referencial na cidade, que não chamamos de lugar físico pelo fato de trabalharmos sempre com a forma material, isto é, não há separação entre forma e conteúdo. Assim a rua, a calçada, as praças, as escadarias e as casas não são apenas formas urbanas, mas desde sempre "formas materiais" onde cidade e história são indissociáveis. 
Nos espaços da cidade, considerados como lugar de manifestação e de liberdade de expressão, diversos tipos de textos circulam no período que antecede as eleições municipais, em diferentes textualidades e materialidades produzidas pelos partidos políticos que procuram convencer o eleitorado quanto às propostas e/ou soluções para administrar a prefeitura da cidade. É importante dizer que essa pluralidade de propostas permite, segundo Neves Filho (2012, p. 20), "o debate ilimitado, para que livres, possam os eleitores responder, positiva ou negativa, aos apelos políticos".

É possível perceber que as histórias da cidade são marcadas por uma diversidade de eventos especiais e habituais, porém o evento mais duradouro é o das propagandas políticas que, além de modificar progressivamente a imagem urbana durante o período que antecede a eleição, se impõem nos espaços modificando a rotina dos sujeitos que a constituem.

Paul Henry (1997, p. 51-52), ao questionar a história das ciências humanas e sociais por considerar que é ilusório colocar para a história uma questão de origem e esperar dela a explicação do que existe, posiciona-se dizendo:

Não há "fato" ou "evento" histórico que não faça sentido, que não peça interpretação, que não reclame que lhe achemos causas e consequências. É nisso que consiste para nós a história, nesse fazer sentido, mesmo que possamos divergir sobre esse sentido em cada caso.

Acompanhando a posição do autor, propomos discutir a constituição históricosocial do processo eleitoral na cidade de Cáceres, a partir da instalação da câmara municipal, quase um século e meio após a sua fundação, a instituição de cargos de governantes e o surgimento das propagandas eleitorais, que no conjunto, reclamam interpretação, por envolver a relação entre língua, sujeito e história.

\section{A Cidade de Cáceres e a Instituição de Cargos Políticos}

A cidade de Cáceres, lócus desta pesquisa, foi criada por determinação de Luiz de Albuquerque de Melo Pereira e Cáceres, Governador e Capitão General do Mato Grosso e Cuiabá, em 6 de outubro de 1778, com o nome de Vila Maria do Paraguai em homenagem à D. Maria I, rainha de Portugal (MENDES, 1998), e ao Rio Paraguai, localizado à margem esquerda da povoação.

Embora a povoação tenha sido fundada com o nome de Vila Maria do Paraguai, para Florence (1977, p. 199), quando de passagem pelo lugar, a Vila era "uma aldeia com um renque de casas em mal estado", e mesmo não apresentando as condições para permanecer com essa denominação manteve-a até 1859. Somente em 1874 foi elevada à categoria de cidade, com o nome de São Luís de Cáceres, e mais de meio século depois, sob o Decreto-Lei estadual $\mathrm{n}^{\circ} 208$, de 26 de outubro de 1938, a cidade é renomeada como Cáceres (MENDES, idem), sem nenhuma determinação, mantendo apenas o sobrenome do fundador português. 
Revisitando a história do Brasil encontramos os primeiros vestígios de instituições e preenchimento de cargos políticos no início da colonização do país, em 1532, com a instalação da primeira Câmara de Vereadores na Vila de São Vicente (São Paulo), na qual os moradores, segundo França $(2008)^{2}$, foram às urnas para eleger o Conselho Municipal, sob a orientação do Livro das Ordenações ${ }^{3}$. Este sistema de escolha é tido como "um processo um tanto complexo", pelo fato de apenas os "homens bons", representantes da sociedade dominante, serem selecionados pelo corregedor (representante do rei) para votar.

De acordo com Ferreira (2005), a convocação dos eleitores era instituída por meio de edital, um documento oficial, afixado em lugares públicos para convocar os "homens bons" 4 e informar sobre a realização da eleição. Os cargos das Câmaras eram preenchidos através de eleições organizadas a cada três anos. Nessas eleições, escolhiam-se entre os "homens bons" três ou quatro vereadores, um escrivão, um tesoureiro e um procurador, além de alguns oficiais da câmara. Os membros eleitos, além de deliberar sobre vários assuntos, eram responsáveis pela organização e administração local.

Esse modelo foi instituído nas cidades e vilas criadas ao longo da colonização brasileira, quer no litoral, quer no interior do país, visto que cada cidade ou vila, uma vez fundada deveria dispor da autoridade de um juiz de câmara e de pelourinho.

$\mathrm{Na}$ ata de fundação da Vila Maria do Paraguay (hoje Cáceres), datada de 6 de outubro de 1778, visualizam-se as futuras construções, incluindo o conselho: "poderão os moradores erigir a sua igreja por ficar a porta principal d'ella para o poente, como o determinam os rituais; e o mais terreno d'esta frente da praça por agora se não ocuparia em casas, deixando-o livre para as do conselho e cadeia quando se deverem fabricar". (grifo nosso).

No entanto, com o passar dos tempos, as câmaras municipais se transformam em executoras das ordens superiores e/ou instrumentos dos todo-poderosos vice-reis, capitães-generais e capitães-mores (FAORO, 2000).

Por outro lado, Silva (2009, p. 4) apregoa que as Câmaras Municipais

exerceram importante papel político na história do Brasil. Seus cargos eram de eleição popular, de modo que elas se colocaram como elo entre o povo e as autoridades gerais. Eram nas Câmaras que transitavam as queixas e os desejos do povo. [...] As Câmaras Municipais eram concebidas como a "cabeça do povo", o que lhes atribuiu um papel político de relevo na independência política, na constitucionalização e na fundação do Império, no século XIX.

\footnotetext{
${ }^{2}$ O Processo Eleitoral no Brasil Colônia (1500-1822), ANAIS do II Encontro Internacional de História Colonial - Revista de Humanidades. UFRN, v. 9, n. 24, set/out. 2008. Disponível em www.cerescaico.ufrn.br/mneme/anais; acesso em jul. 2014.

${ }^{3}$ Livro máximo do Reino de Portugal, que estabelecia os fundamentos jurídicos da Monarquia, no âmbito nacional, e das repúblicas das vilas e cidades, no âmbito local (cf. FERREIRA, 2005, p. 28).

${ }^{4}$ Aqueles que pertenciam à nobreza das vilas e cidades (ibidem, p. 32), ou de acordo com Silva (2009, p.

4), pertenciam à nobreza, milícia e clero.
} 
Como o período colonial não dispunha de um sistema eleitoral próprio, as Ordenações do Reino vigoraram até a metade do século XIX. Ferreira (2005) assinala que, por decreto de 3 de junho de 1822, D. Pedro convoca a Assembleia Geral Constituinte e Legislativa composta de deputados das províncias do Brasil eleitos na forma das Instruções, que passam a constituir a primeira lei eleitoral brasileira, ou seja, fundando o dizível da primeira lei para presidir as eleições no Brasil.

Para Ferreira (ibidem, p.73-74), "não havia, ainda, partidos políticos. O sistema era indireto, em dois graus: o povo escolhia os eleitores, os quais, por sua vez, iriam eleger os deputados". O processo político-eleitoral dessa época mostra que os candidatos escolhidos pelo povo, denominados eleitores de paróquia, deveriam ser homens livres e católicos maiores de 25 anos com renda de cem mil réis anuais. Desse modo, cabia ao povo apenas a escolha indireta dos candidatos.

O Império, a partir das Instruções ou Lei Eleitoral de 26 de março de 1824, para a eleição de senadores, deputados e membros das Assembleias Legislativas Provinciais, passa a aprimorar o processo eletivo com a criação de duas leis, a de $1^{\circ}$ de outubro de 1828, para as eleições municipais (vereadores); e a de 12 de agosto de 1834, para a eleição de regente ${ }^{5}$.

Com o advento da República, a Assembleia Constituinte eleita teve como missão elaborar uma nova Constituição que, promulgada em 1891, aboliu a exigência de renda para ser eleitor ou candidato, o direito de voto passa a ser garantido aos brasileiros maiores de 21 anos, mas continuavam excluídos desse direito os analfabetos, soldados, religiosos e mulheres.

Segundo Mendes (2009), a Lei de $1^{\circ}$ de outubro de 1828, denominada "Regimento Interno das Câmaras Municipais do Império", substitui as Ordenações do Reino, e passa a vigorar nos municípios até o ano de 1891, quando se separam as funções deliberativa e executiva, ficando a última a cargo de um Intendente Geral.

Com a instituição da República no Brasil, Mato Grosso deixa de ser província e se torna Estado, conforme o Decreto $n^{\circ} 1$, de 15 de novembro de $1889^{6}$. Nessa transição, o General Antonio Maria Coelho, aclamado pelo povo e pela Assembleia Provincial, é nomeado Governador de Mato Grosso. O Estado, nessa configuração política, passa a ter autonomia na organização do processo eleitoral de governantes e representantes das assembleias legislativas, e na constituição de regras para escolha dos representantes políticos dos municípios, conforme os artigos 45,46 e 47, da Constituição ${ }^{7}$ Estadual de 1891:

Artigo 45- O Município será autônomo e independente na gestão dos seus negócios.

\footnotetext{
${ }^{5}$ Conforme Ferreira (2005), o imperador é considerado menor até os 18 anos de idade, durante essa fase o Império é governado por uma Regência, a qual pertencerá ao parente mais próximo do imperador, de acordo com a ordem da sucessão, e que tenha mais de vinte e cinco anos. Caso o imperador não tenha parente com essas qualidades, o império será governado por uma Regência permanente (nomeada pela Assembleia Geral), tendo três membros, sendo que o mais velho em idade será o presidente.

6 Disponível em http://www2.camara.leg.br/legin/fed/decret/1824-1899/decreto-1-15-novembro-1889532625-publicacaooriginal-14906-pe.html; acesso em ago. 2014.

${ }^{7}$ Cf. Mendes (2009, p. 60).
} 
Artigo 46- O governo do município será cometido, na parte deliberativa, a uma Câmara cujos membros denominar-se-ão vereadores, e, na parte executiva, a um cidadão com o título de Intendente Geral. (Grifo nosso).

Artigo 49 - Os vereadores, o Intendente e os Vice-Intendentes serão eleitos na mesma ocasião por sufrágio direto e por pluralidade de votos e servirão durante quatro anos, não podendo ser reeleito o Intendente e seus substitutos. (grifo nosso).

No período entre a fundação da Vila Maria do Paraguay (1778) e a primeira eleição para Intendente Geral da cidade de Cáceres, em 1892, não constam nos registros históricos do município documentos que dizem sobre o funcionamento da Câmara e nem dos nomes dos vereadores que a constituíram. No entanto, com a criação do Conselho de Intendentes pelo governo republicano, observamos no registro da ata, de 17 de fevereiro de 1890, a extinção da Câmara: "[...] O presidente da Câmara fez o relatório da sua administração e finda a leitura [...] e nomeou uma comissão para despedir os membros da extinta Câmara"8. O acontecimento dessa ata, em que foi dada posse aos Intendentes do Conselho Municipal de Cáceres, nos leva a pressupor que, anterior a esse período funcionou na Vila Maria a Câmara Municipal nos moldes das demais câmaras brasileiras.

Retomando a eleição e o preenchimento de cargo de vereadores, intendentes e vice-intendentes, a primeira eleição para esses cargos aconteceu em 16 de novembro de 1892. Esses cargos foram mantidos até a criação do cargo de prefeito que foi preenchido pela primeira vez, na cidade de Cáceres, por Joaquim Augusto da Costa Marques, nomeado pelo governo estadual em 1931. Esse sistema de nomeação se manteve até as eleições municipais ocorridas em 1937.

Durante o primeiro governo Getulista (1930-1937), criam-se a Justiça Eleitoral, a instituição do voto feminino, a elaboração do Código eleitoral (1932) ${ }^{9}$ e a Constituição de 1934. Porém, no governo de 1937 a 1945, Getúlio Vargas extingue os direitos políticos dos brasileiros, impede qualquer tipo de participação política, instituindo uma ditadura que se prolongou até 1945 .

De 1946 a 1964, período denominado República Populista, as políticas do Governo se revestiam de valores populistas, o que contribuiu para a deposição de João Goulart, da presidência do Brasil em 1964, dando início aos governos militares, conhecido como o "golpe militar", marcado como o período da ditadura que se estende até 1985, em que os governos restringem o funcionamento das instituições democráticas, suspendem os direitos políticos e fecham o Congresso Nacional.

Durante a ditadura militar, assim como outros municípios localizados na faixa de fronteira, Cáceres foi considerada zona de segurança nacional, o que dava ao Governador o direito de indicar e nomear os prefeitos municipais (MENDES, 2009).

O ano de 1985 é considerado um marco histórico na política brasileira com a eleição de um presidente civil, finalizando duas décadas do poder militar. Com a

\footnotetext{
${ }^{8} C f$. ata de reunião extraordinária dos Intendentes (MENDES, 2009, p.58-59).

9 Conforme afirma Vera Chaia, no artigo "A longa conquista do voto na história política brasileira", disponível em http://ww, no artigo "w.pucsp.br/fundasp/textos/downloads/O voto no Brasil.pdf; acesso em jun. 2014.
} 
instalação da Nova República, retoma-se o processo democrático com eleições diretas para cargos do executivo em níveis nacional, estadual e municipal, e em Cáceres, elegese para prefeito, pelo voto popular, Antonio Carlos Souto Fontes.

Podemos dizer que a história política da cidade de Cáceres vivenciou os reflexos dos períodos de exceção e da participação popular com menos intensidade que nos grandes centros urbanos, dada a sua localização geográfica e a dificuldade de comunicação.

Cabe-nos observar que a partir da redemocratização política do país inaugura-se um novo processo eleitoral para o preenchimento de cargos executivo e legislativo, para o qual a propaganda política e/ou eleitoral tem se colocado como crucial para a campanha dos candidatos em todo o território nacional.

\section{As Propagandas e o TSE}

O cenário eleitoral nas cidades brasileiras, no intervalo de quatro a quatro anos, é marcado por momentos de reafirmação da cidadania. $O$ voto passa a ser configurado como poder de escolha, decisivo para dar estabilidade política ao regime democrático representativo. O jogo simbólico entre eleitor e candidato é sustentado por tomadas de decisões construídas pelo candidato, cuja legitimação é confirmada nas urnas. Desse modo, a propaganda eleitoral, de forma direta, nada mais é do que o pedido direto do voto aos eleitores.

No entanto, para que ocorra essa legitimação, entra em cena a propaganda eleitoral regida pela Lei Eleitoral 9.504/97, a qual tem como finalidade, segundo Filho (2012, p. 50), "a cooptação lícita da vontade do eleitor e do seu voto". A propaganda eleitoral, conhecida também como propaganda política eleitoral, segundo Ramos (2005, p. 14), é "uma forma de capacitação de votos usada pelos partidos políticos, coligações, ou candidatos, em época determinada por lei”, a partir da circulação de suas propostas com vistas à eleição do cargo eletivo como a que estamos tratando neste estudo, do cargo eletivo à Prefeitura do município de Cáceres-MT.

Já a propaganda partidária ou propaganda política para o autor significa a "divulgação genérica" no período da eleição, ou fora dela de forma exclusiva do programa e da proposta política do partido, sem mencionar nomes de candidatos, exceto os partidários à procura de adeptos.

Conforme Ramos (ibidem, p. 12), o termo "propaganda" é o gerúndio latino do verbo propagar, e significa "propagar", "multiplicar" ou "reproduzir". "Um conceito criado pela Igreja católica, com o intuito religioso e que mais tarde passou a adquirir natureza política". De acordo com Capelato (2009 apud NEVES FILHO, 2012, p. 18), "a propaganda política constitui, um elemento preponderante da política de massas que se desenvolveu no período entre guerras com base nas críticas ao sistema liberal considerado incapaz de solucionar os problemas sociais". Neves Filho (2012) reflete que, no final do século XIX e início do século XX, os condutores das massas tentavam substituir a ideia 
da identidade individual própria do liberalismo pela identidade nacional na forma coletiva, correspondente "à ideia/imagem da sociedade unida e harmônica, guiada pelo líder, condutor das massas" (idem).

Com a popularização, em meados do século $\mathrm{XX}$, dos meios de comunicação, a propaganda política nas emissoras de rádio e televisão, e mais recentemente na internet, faz surgir o marketing político que, em 1956, já se tornava um instrumento indispensável às campanhas. $\mathrm{O}$ marketing político, de acordo com Lima $(2002)^{10}$, é o conjunto de atividades que visa a garantir maior adesão possível a uma ideia ou a uma causa que pode ou não ser encarnada na figura de uma pessoa, normalmente um político.

Como vimos, as técnicas para a disseminação da propaganda política são inúmeras, o que nos faz referir a Goebbels (apud DOMENACH, 2002, p. 30) que diz: "Fazer propaganda é falar de uma ideia por toda a parte, até nos bondes. A propaganda é ilimitada em suas variações, em sua flexibilidade de adaptação e em seus efeitos". Domenach (ibidem, p. 38) afirma que toda campanha de propaganda deve prezar a qualidade fundamental: "a permanência do tema, aliado à variedade de apresentação".

No Brasil, Prudente de Moraes, em campanha eleitoral, montou sua estratégia de propaganda política para chegar ao posto máximo aspirado por um político, o de presidente da República, no ano de 1894. Durante todo o percurso de sua carreira política trabalhou muito sua imagem pública ${ }^{11}$. Realizava comícios em muitas cidades do interior, locomovendo-se de trens ou "até mesmo no lombo de um burro". O político possuía uma caderneta de endereços com os principais nomes de interlocutores, a quem pedia voto e dinheiro para sua campanha eleitoral ${ }^{12}$, ou seja, eram práticas políticas dadas as condições sociais e históricas da época. Com o passar do tempo, inúmeras inovações foram ocorrendo em relação à propaganda política nas cidades brasileiras, como o emprego das fotografias, faixas, placas e cartazes ao longo das ruas e a entrega de brindes e flâmulas dos candidatos ${ }^{13}$.

Quanto à regulamentação da propaganda eleitoral no plano nacional, convém destacar que mesmo com o primeiro Código Eleitoral brasileiro de 1932, conforme Ramos (2005, p. 77), "a primeira lei que tratou da regulamentação da propaganda eleitoral foi a de $\mathrm{n}^{\circ} 1.164$, de 24 de julho de 1950, que instituiu o terceiro Código Eleitoral brasileiro". Ainda, segundo o autor, as campanhas eleitorais, até então, eram feitas basicamente através de comícios em palanques instalados nos espaços principais da cidade, e de rádio, um instrumento que possibilitava a chegada das propagandas às casas dos eleitores. Com a edição da Lei 9.504, de 30 de setembro de 1997, institui-se a regulamentação da propaganda eleitoral, que a rege até a atualidade.

\footnotetext{
${ }^{10}$ Em Marketing Eleitoral, versão para eBook, fonte digital disponível, em www.ngarcia; acesso em jul. 2014.

${ }^{11}$ Prudente de Moraes e os primórdios da propaganda política. Texto apresentado na "Sessão Coordenada História da Comunicação/Política", no I Congresso Anual da Associação Brasileira de Pesquisadores de Comunicação e Política, realizado na Universidade Federal da Bahia em 2006. Texto disponível em http://www.compolitica.org/home/wp-content/uploads/2010/11/Queiroz_e_Romanini\%25202006.pdf; acesso em jul. 2014.

12 Ver Ramos (2005).

${ }^{13}$ Idem.
} 
Ao longo dos anos em que a cidade de Cáceres vivenciou campanhas eleitorais para os cargos eletivos do executivo e legislativo em nível nacional, estadual e municipal, proliferavam-se as propagandas nas rádios, nas ruas, nos postes, muros, o que causava uma forte poluição visual aos espaços da cidade. Sob o efeito do abuso e da falta de regularidade, o Tribunal Superior Eleitoral (TSE) passa a intervir, limitando esses lugares por meio de normas jurídicas eleitorais.

Nos anos finais do século XX, ao se aproximar o período das eleições, as ruas das cidades brasileiras - capitais e interior, eram tomadas por carros de som, alto-falantes, e por uma profusão de cartazes afixados em espaços públicos e privados.

As propagandas realizadas de forma irregular traziam um grande incômodo à população. Constantemente, candidatos/partidos que agiam com irregularidade quanto à disseminação das propostas, eram notificados e multados, porém, muitos deles voltavam a agir da mesma forma, infringindo a legislação da campanha eleitoral.

Com o passar dos anos, o TSE faz algumas alterações na Lei Eleitoral, determinando os locais públicos para fixação de propagandas eleitorais nos espaços da cidade no período da campanha eleitoral, acontecimento que produziu o interpretável da formulação, pelo Tribunal Regional Eleitoral de Mato Grosso (TRE), de uma Cartilha com o objetivo de orientar os partidos políticos, candidatos, eleitores e demais envolvidos nas eleições municipais de 2012, quanto às normas relativas à Propaganda Eleitoral ${ }^{14}$, como mostram os parágrafos abaixo do artigo 37:

$\S 6^{\circ}$ É permitida a colocação de cavaletes, bonecos, cartazes, mesas para distribuição de material de campanha e bandeiras ao longo das vias públicas, desde que móveis e que não dificultem o bom andamento do trânsito de pessoas e veículos. (Incluído pela Lei no 12.034, de 2009).

$\S 7^{\circ}$ A mobilidade referida no $\S 6^{\circ}$ estará caracterizada com a colocação e a retirada dos meios de propaganda entre as seis horas e as vinte e duas horas. (Incluído pela Lei ${ }^{\circ}$ 12.034, de 2009; grifo nosso).

Durante o período eleitoral, mesmo com essa regulamentação, é possível observar na cidade de Cáceres como em outras cidades do país diversos materiais de propagandas políticas, espalhados em lugares proibitivos, como nas rotatórias, nas ruas, nas calçadas, nos espaços particulares (como muros de residências e comércios), que constituem um nível exacerbado de poluição visual.

A lei resguarda a cidade e os cidadãos em relação à sonoridade dos alto-falantes, no período das vinte e duas horas até às oito da manhã, conforme o $\S 3^{\circ}$ do Art. 38:

$O$ funcionamento de alto-falantes ou amplificadores de som, ressalvada a hipótese contemplada no parágrafo seguinte, somente é permitido entre as oito e as vinte e duas horas, sendo vedados a

\footnotetext{
${ }^{14}$ Conforme o Presidente do Tribunal Regional Eleitoral, na apresentação da Cartilha, salienta que ela não substitui a leitura da legislação eleitoral, da jurisprudência e doutrina sobre o tema, pois esse material seria uma contribuição para o aprimoramento das instituições democráticas no Estado de Mato Grosso. Disponível em http://apps2.tre-mt.jus.br/subsite/eleicoes_2012/cart.asp; acesso em jul. 2014.
} 
instalação e o uso daqueles equipamentos em distância inferior a duzentos metros: (grifo nosso)

I - das sedes dos Poderes Executivo e Legislativo da União, dos Estados, do Distrito Federal e dos Municípios, das sedes dos Tribunais Judiciais, e dos quartéis e outros estabelecimentos militares;

II - dos hospitais e casas de saúde;

III- das escolas, bibliotecas públicas, igrejas e teatros, quando em funcionamento.

Além do tempo estabelecido para a propaganda eleitoral, legalmente surge outro limite decorrente da natureza dos bens, como pode ser visto no Artigo 37 da Lei 9.504/97, fazendo emergir uma contradição entre o que é proibido e o que não é proibido durante a campanha.

O artigo abaixo diz sobre a proibição da propaganda em espaços públicos:

Nos bens cujo uso dependa de cessão ou permissão do Poder Público, ou que a ele pertençam, e nos de uso comum, inclusive postes de iluminação pública e sinalização de tráfego, viadutos, passarelas, pontes, paradas de ônibus e outros equipamentos urbanos, é vedada a veiculação de propaganda de qualquer natureza, inclusive pichação, inscrição a tinta, fixação de placas, estandartes, faixas e assemelhados. (Redação dada pela Lei $\mathrm{n}^{\circ} 11.300$, de 2006; grifo nosso)

No entanto, no segundo parágrafo do mesmo artigo, autoriza-se o uso de propaganda, como podemos ver:

$\S 2^{\circ}$ Em bens particulares, independe de obtenção de licença municipal e de autorização da Justiça Eleitoral a veiculação de propaganda eleitoral por meio da fixação de faixas, placas, cartazes, pinturas ou inscrições, desde que não excedam a $4 \mathrm{~m}^{2}$ (quatro metros quadrados) e que não contrariem a legislação eleitoral, sujeitando-se o infrator às penalidades previstas no $\S 1^{\circ}$. (Redação dada pela Lei ${ }^{\circ}$ 12.034, de 2009; grifo nosso)

Entre o artigo 37 que "veda" e o seu $\S 2^{\circ}$ que autoriza o uso de espaços particulares para fixação de propagandas eleitorais ocorre um deslocamento de sentidos, visto que os sentidos podem ser outros, mas não qualquer um entre o que disciplina a lei, no que tange ao uso público e ao uso privado para veiculação das propagandas eleitorais.

O recorte acima põe "em funcionamento o conjunto do que é preciso não dizer para poder dizer" (ORLANDI, 1993, p. 76). Ou seja, "o silenciamento aí funciona como forma não de calar, mas de fazer dizer uma coisa, para deixar de dizer outras" (idem, p. $55)$.

Segundo Pêcheux (2011, p. 74), "a propaganda se faz com imagens e palavras, sentimentos, ideias e gestos. É, pois, evidentemente, um negócio de psicologia". Complementa, ainda, dizendo:

Não repetiremos jamais em demasia: é importante, camaradas, a psicologia! É muito importante, na luta de classes, para ser capaz de responder no terreno da propaganda. Levar em conta o que as pessoas 
têm na cabeça. Saber como se endereçar a elas, saber tocá-las, quebrar os refrãos, encontrar o novo. Saber comunicar. Se ajustar às pessoas, para melhor ajustá-las, por todos os meios, para melhor mirar, nós também, o alvo de suas cabeças. Não hesitemos: vamos à psicologia, base científica da propaganda! Vamos aos especialistas da propaganda! (PÊCHEUX, 2011, p. 74)

Os slogans políticos, constitutivos das propagandas eleitorais, funcionam como textos, produzindo sentidos na/pela cidade e também para os sujeitos citadinos, e se movimentam associados às figuras de cada candidato, juntamente com as cores partidárias que os distinguem para o público que desejam atingir, mostrando que o sentido não é único e nem tão pouco transparente.

Figueiredo (2005 apud CARROZA, 2011, p. 82-83) diz que o slogan é "como aquilo que traz para o anunciante a responsabilidade do que é dito", "uma forma mais sintética de posicionamento da empresa", "é o espaço ideal para a afirmação do posicionamento, da personalidade da marca".

Assim, pensar os textos/slogans na campanha eleitoral é observar as condições político-ideológicas dos sujeitos que os formulam, considerando que "a análise do sentido da linguagem deve localizar-se no estudo da enunciação, do acontecimento do dizer". (GUIMARÃES 2002, p.7).

\section{O Funcionamento das Propagandas na Cidade de Cáceres}

Antes da data prevista em lei para o início da campanha eleitoral, os espaços da cidade são tomados por anúncios comerciais em outdoors, painéis afixados em muros, além de propagandas de eventos culturais, musicais e políticos. Com a instalação das campanhas eleitorais dos candidatos, a cidade é inundada por propagandas políticas afixadas em cavaletes, cartazes, faixas, e em bandeiras que tremulam sob as mãos daqueles que prestam serviços aos candidatos em pontos estratégicos da cidade, encarregados de propagar a sigla partidária e o número do candidato, que interpelam direta e indiretamente os que trafegam a pé, de moto, de bicicleta ou de carro. Essas propagandas político-partidárias vêm juntar-se às de publicidade comercial já existente, poluindo o visual dos espaços públicos urbanos.

Com essas imagens, os espaços públicos como avenidas e ruas margeadas ou não por canteiros, durante o período eleitoral, perdem a função que as particularizam, e passam a ter outras funcionalidades a partir das relações de ocupação desses espaços por instrumentos de campanhas utilizados pelos agentes políticos que, segundo Zattar (2009, p. 74), "ao desenvolverem determinadas práticas sociais e de linguagem, emprestam aos espaços da cidade novas identidades". As diferentes formas de ocupação e de (re)funcionalidade dos espaços públicos são chamadas pela autora de "invasionismos".

Chamam a atenção do leitor, também nesse período, as propagandas de cada candidato que se distinguem pela forma, slogan/enunciado, cor, e principalmente pela 
foto do candidato e a sigla do partido à qual pertence, cujas imagens projetadas na urna eletrônica 'ajudam' o eleitor a reconhecê-las no momento do voto.

As propagandas em espaço aberto são criadas pelo marketing político de cada candidato, estrategicamente para o público eleitor, e uma vez afixadas em cavaletes funcionam como paisagens inscritas no corpo da cidade, espacializando a linguagem na/pela cidade, para aqueles que entram a cidade e saem dela, como podemos ver nas imagens que se seguem.

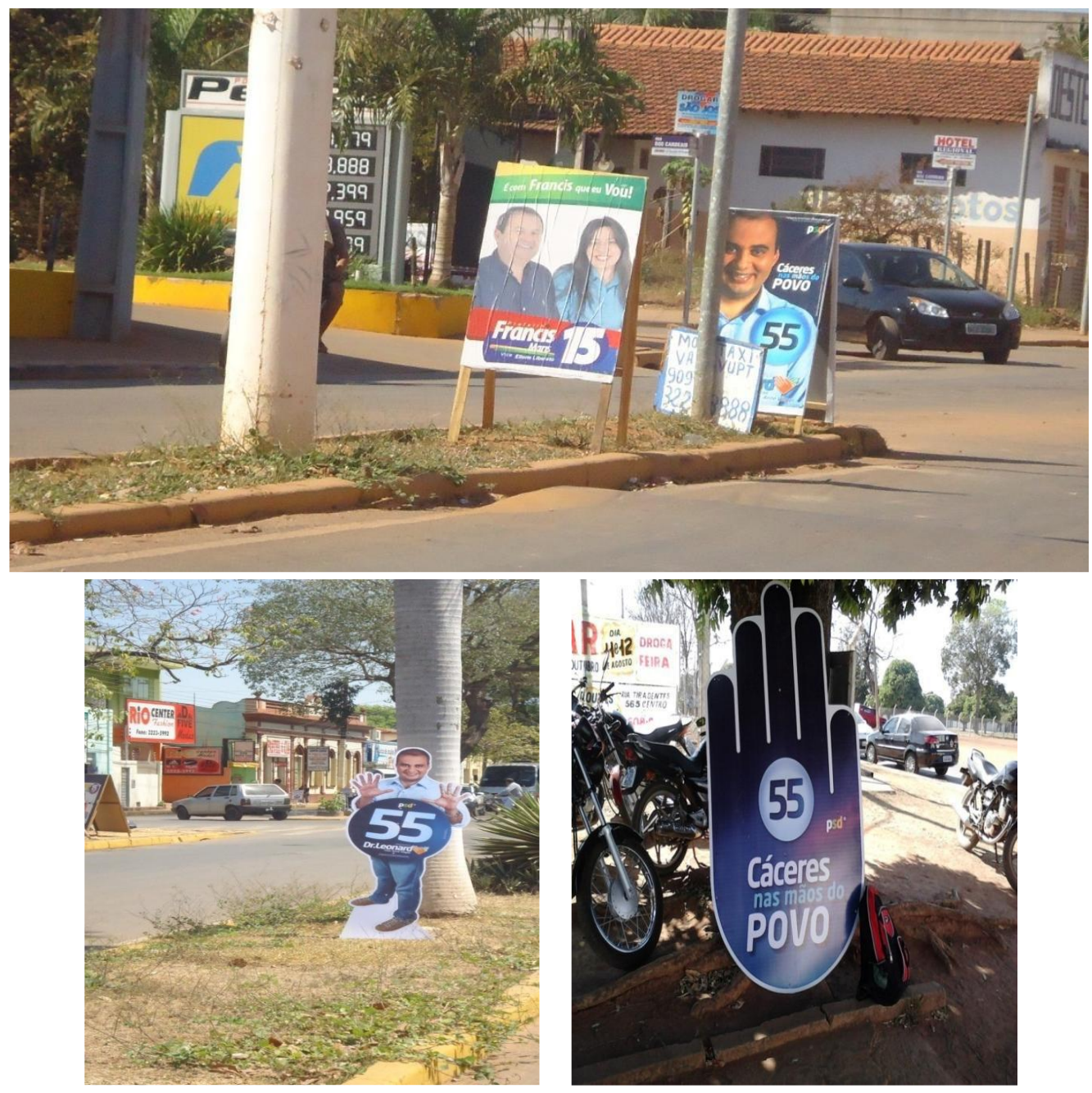

As propagandas - materiais permitidos legalmente, instaladas nos canteiros e calçadas paralelos às ruas da cidade, funcionam simbolicamente como uma morfologia urbana que sinaliza para os transeuntes que esses espaços públicos, por um determinado tempo, ficam à disposição dos partidos políticos, e perdem a finalidade para a qual foram construídos.

Vejamos o $\S 3^{\circ}$ do artigo 37 da Lei Eleitoral 9.504/97 que regulamenta o impedimento de propagandas eleitorais nos espaços da cidade. 
Nas árvores e nos jardins localizados em áreas públicas, bem como em muros, cercas e tapumes divisórios, não é permitida a colocação de propaganda eleitoral de qualquer natureza, mesmo que não lhes cause dano. (grifo nosso).

A apropriação dos espaços na cidade (re)significa, de um lado, a cidade atravessada pelos sentidos da campanha eleitoral, mudando o seu aspecto ambiental e, por outro lado, a apropriação desses espaços toma a linguagem como observatório do urbano em um duplo movimento: o espaço urbano que se diz e da linguagem que a espacializa ${ }^{15}$.

Já o parágrafo $6^{\circ}$ do Art. 37, da mesma lei eleitoral, regulamenta a permissão de material de campanha em espaços públicos urbanos:

É permitida a colocação de cavaletes, bonecos, cartazes, mesas para distribuição de material de campanha e bandeiras ao longo das vias públicas, desde que móveis, e que não dificultem o bom andamento do trânsito de pessoas e veículos. (Incluído pela Lei n ${ }^{\circ}$ 12.034, de 2009; grifo nosso)

O parágrafo acima, ao mesmo tempo em que permite o uso de material físico, delimita o tipo, desde que tenha mobilidade e não interfira no trânsito das pessoas e dos veículos. A ordenação jurídica da Lei Eleitoral não diz sobre tamanhos e/ou formas dos materiais, abrindo brechas para que se produzam outros materiais alternativos como o cartaz em forma de uma mão instalado no tronco de uma árvore, colocação que desrespeita o dispositivo da lei.

Além dos espaços determinados pela justiça para afixação dos materiais de propaganda ao longo das vias públicas, observa-se a distribuição de santinhos e de outros materiais de campanha, como adesivos, revistas e panfletos com propostas, que, usados pelos candidatos ou grupos/cabos eleitorais durante as visitas aos bairros, centros comunitários, residências, vão ficando sobre os espaços das calçadas principalmente, constituindo-se em lixo urbano.

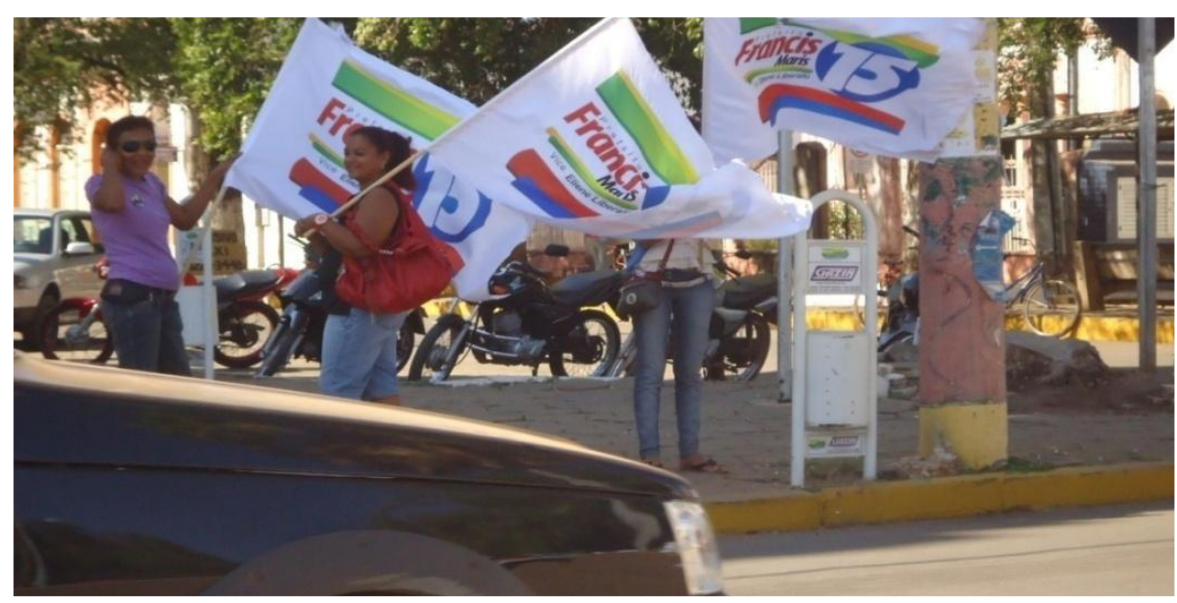

\footnotetext{
${ }^{15}$ Cf. contracapa do livro Cidade atravessada: os sentidos públicos no espaço/urbano, de Eni Orlandi, 2001.
} 


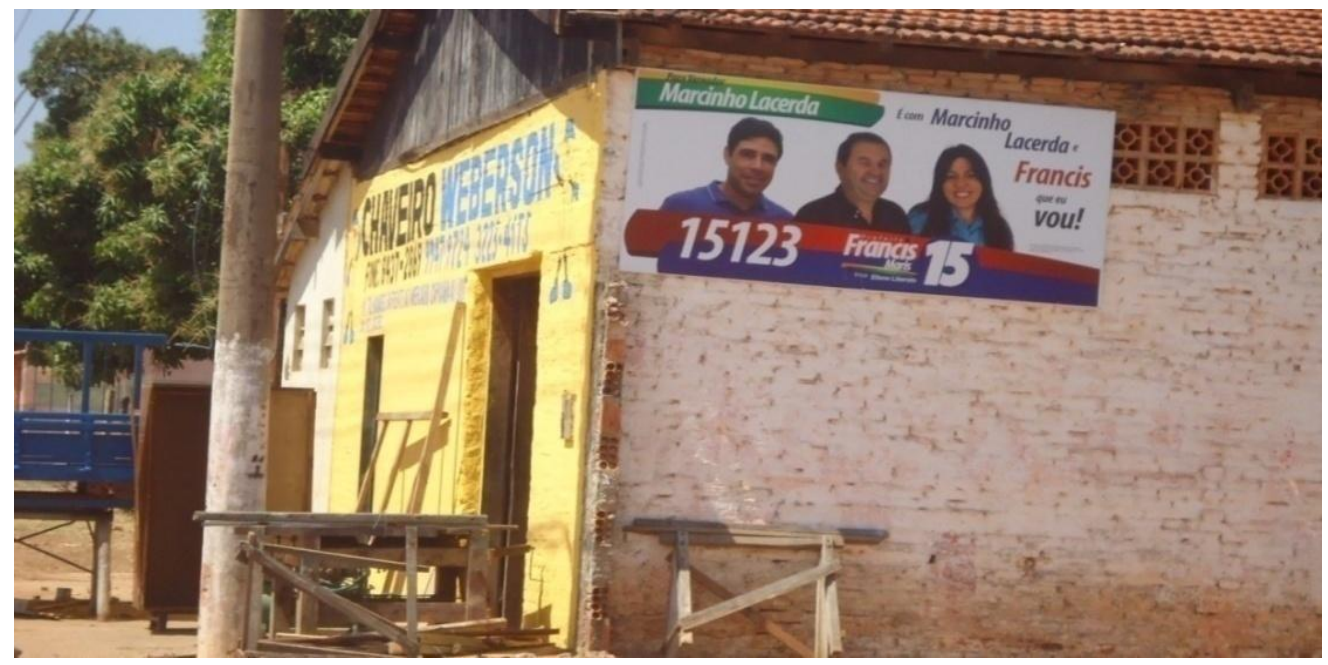

Notamos que durante a campanha eleitoral, os candidatos se munem de estratégias políticas com o intuito de produzir no eleitorado sentidos de engajamento às propostas dos candidatos. Desse modo, os slogans políticos são utilizados pelos candidatos com forte apelo para a promoção da sua imagem e de sua proposta política.

Neste percurso, vemos que a propaganda política é o principal recurso dos candidatos; como já diziam os gregos, de acordo com muitos estudiosos, as palavras têm poder de persuadir, intimidar, convencer, inocentar ou condenar, de fazer crer, de eleger.

\section{Considerações finais}

Nos estudos que empreendemos, mostramos como a cidade é vista por diferentes áreas do conhecimento em sua forma material e histórica. Mostramos também como se dá a constituição do processo sócio-histórico eleitoral da cidade de Cáceres, a instituição para os cargos de intendente e prefeito, bem como o surgimento das propagandas eleitorais, e as estratégias políticas empregadas durante a campanha pelos candidatos em nível nacional, estadual e municipal, de acordo com os regimes políticos instalados no país.

Discutimos o funcionamento das propagandas nos espaços da cidade, a instituição da Lei 9.504/97, que regulamenta o processo eleitoral durante o período de campanha, mostrando o deslocamento de sentidos entre o que diz a lei e a sua efetivação, visto que os sentidos da lei não são fechados, podem ser sempre outros, pois o que se diz é incontornavelmente construído na linguagem.

Desse modo, como tratamos de campanha eleitoral, de disputas políticas entre sujeitos que buscam a mesma finalidade, e que se colocam em um espaço de enunciação regulado e de disputas pela palavra e pelas línguas, tomamos, nesta pesquisa, o político não como discussões eleitoreiras, mas como o "fundamento das relações sociais, no que tem importância central a linguagem" (GUIMARÃES, 2002, p. 16). E essa relação se 
torna fundamental à vida social e política, pelo fato de o homem estar sempre sujeito a assumir a palavra, mesmo que lhe seja negada.

\section{Referências bibliográficas}

CARROZA, Newton Guilherme. O(s) logos da cidade. Em: ORLANDI, Eni P. (Org.). Discurso, espaço, memória.Caminhos da identidade no sul de Minas. Campinas: Editora RG, 2011.pp. 81-94.

DOMENACH, Jean-Marie (2002). A propaganda política. Disponível em http://www.ebooksbrasil.org/eLibris/proppol.html; acesso em jul. 2014.

FERREIRA, Manuel Rodrigues. A evolução do sistema eleitoral brasileiro. Brasília: Senado Federal; Conselho Editorial, 2005.

FAORO, Raymundo. Os donos do poder: formação do patronato brasileiro. 10a . ed. São Paulo: Globo, 2000.

GUIMARÃES, Eduardo. Semântica do acontecimento: um estudo enunciativo da designação. Campinas, SP: Pontes, 2002.

HENRY, Paul. A história não existe? Em: ORLANDI, Eni et al. Gestos de leitura: da história no discurso. Trad. Bras. 2a . ed. Campinas, SP: Ed. da Unicamp, 1997. pp. 29-53.

LEFEBVRE, Henri. O direito à cidade. São Paulo: Centauro, 2001.

LE GOFF, Jaques. Por amor às cidades. São Paulo: Editora da UNESP, 1998.

MENDES, Natalino Ferreira. História de Cáceres: história da administração municipal. Cáceres: Editora UNEMAT, 2009.

NEVES FILHO, Carlos. Propaganda eleitoral e o princípio da liberdade da propaganda política. Belo Horizonte: Fórum, 2012.

ORLANDI. Eni. P. Cidade dos sentidos. Campinas, SP: Pontes, 2004.

(Org.). Cidade atravessada: os sentidos públicos no espaço urbano. Campinas, SP: Pontes, 2001.

As formas do silêncio: no movimento dos sentidos. Campinas, SP: Editora da Unicamp, 1993.

PÊCHEUX, Michel. Foi “propaganda" mesmo o que você disse? [1979] Em: ORLANDI, Eni (Org.). Análise de Discurso: Michel Pêcheux (Textos escolhidos). Campinas, SP: Pontes, 2011. 
PFEIFFER, Cláudia C. Cidade e sujeito escolarizado. Em: ORLANDI, Eni. (Org.). Cidade atravessada: os sentidos públicos no espaço urbano. Campinas, SP: Pontes, 2001. pp. 29-33.

RAMOS, Wolney. Regime jurídico da propaganda política. São Paulo: SP, 2005.

ROLNIK, Raquel. O que é cidade. São Paulo: Editora Brasilense, 1988.

SILVA, Karla Maria da. O papel das câmaras municipais no Brasil colonial: novas possibilidades de análise. ANPUH, XXV Simpósio Nacional de História, Fortaleza, 2009. Disponível em http://anpuh.org/anais/wpcontent/uploads/mp/pdf/ANPUH.S25.1251.pdf; acesso em ago.2014.

ZATTAR, Neuza B. da Silva. Calçadas: espaços públicos ou privados? Línguas e instrumentos linguísticos, Unicamp, Campinas, Editora RG, nº 23/24, pp. 73-82, 2009.

Para citar este texto:

SERAGLIO, Jucineia; ZATTAR, Neuza Benedita da Silva. A cidade de Cáceres: história e memória do processo eleitoral. Entremeios [Revista de Estudos do Discurso], Seção Estudos, Programa de Pós-graduação em Ciências da Linguagem (PPGCL), Universidade do Vale do Sapucaí, Pouso Alegre (MG), vol. 12, p. 65-80, jan. - jun. 2016. DOI: http://dx.doi.org/10.20337/ISSN2179-3514revistaENTREMEIOSvol12pagina65a80 